University of Nebraska - Lincoln

DigitalCommons@University of Nebraska - Lincoln

Biological Systems Engineering: Papers and

Publications

Biological Systems Engineering

2-20-2019

\title{
Quantifying and correcting for clay content effects on soil water measurement by reflectometers
}

Jasreman Singh

Tsz Him Lo

Daran Rudnick

Suat Irmak

Humberto Blanco-Canqui

Follow this and additional works at: https://digitalcommons.unl.edu/biosysengfacpub

Part of the Bioresource and Agricultural Engineering Commons, Environmental Engineering Commons, and the Other Civil and Environmental Engineering Commons

This Article is brought to you for free and open access by the Biological Systems Engineering at DigitalCommons@University of Nebraska - Lincoln. It has been accepted for inclusion in Biological Systems Engineering: Papers and Publications by an authorized administrator of DigitalCommons@University of Nebraska Lincoln. 


\title{
Quantifying and correcting for clay content effects on soil water measurement by reflectometers
}

\author{
Jasreman Singh, ${ }^{1}$ Tsz Him Lo, ${ }^{1}$ Daran R. Rudnick, ${ }^{1}$ \\ Suat Irmak, ${ }^{1}$ and Humberto Blanco-Canqui ${ }^{2}$
}

\footnotetext{
1 Department of Biological Systems Engineering, University of Nebraska-Lincoln, USA

2 Department of Agronomy and Horticulture, University of Nebraska-Lincoln, USA

Corresponding author - D. R. Rudnick, 402 West State Farm Road, North Platte, NE 69101, USA, email daran.rudnick@unl.edu
}

\begin{abstract}
The presence of clay particles increases the specific surface area of a soil and can affect the calibration of electromagnetic soil water sensors including reflectometers. To quantify and correct for this effect in two relatively new reflectometers, three TDR315 and three CS655 sensors were installed in each of five soils with clay content ranging from 5 to $49 \%$. As the soils were dried in a temperature controlled room, sensor reported soil volumetric water content $\left(\theta_{v}\right)$ according to the factory calibration was compared against reference $\theta_{\mathrm{v}}$ determined by weighing the soils. Sensor reported $\theta_{v}$ was similar to reference $\theta_{v}$ in the sand soil (root mean square difference (RMSD) $<0.02 \mathrm{~m}^{3} \mathrm{~m}^{-3}$ ), but the discrepancy was larger for the clayey soils. An increase in clay content tended to cause TDR315 to underestimate low $\theta_{\mathrm{v}}$ and tended to cause CS655 to overestimate $\theta_{\mathrm{v}}$ in a concave down pattern. At the levels evaluated in this experiment, differences in clay content produced a larger effect
\end{abstract}

Published in Agricultural Water Management 216 (2019), pp 390-399.

doi:10.1016/j.agwat.2019.02.024

Copyright (c) 2019 Elsevier B.V. Used by permission.

Submitted 6 April 2018; revised 6 February 2019; accepted 10 February 2019; published 20 February 2019. 
than differences in temperature $\left(24\right.$ versus $35^{\circ} \mathrm{C}$ ) and salinity (o versus $3.09 \mathrm{~g} / \mathrm{L}$ $\mathrm{CaCl}_{2}$ ) on factory calibration accuracy of both sensors. Soil specific empirical calibrations developed using a square root mixing model fitted the experimental data very closely $\left(\mathrm{R}^{2}>0.93\right)$ for both sensors. By estimating calibration coefficients based on clay content alone to recalculate sensor $\theta_{v}$ from sensor reported apparent relative permittivity, RMSD from reference $\theta_{\mathrm{v}}$ was reduced by approximately $36 \%$ for both sensors as compared with using the factory calibration. Applying the same procedure to independent literature data tended to improve $\theta_{\mathrm{v}}$ accuracy of both sensors increasingly as clay content increased above $20 \%$. The findings suggest that a simple, user-friendly correction for clay content effects may provide initial practical improvement over the factory calibration of a reflectometer in clayey soils.

Keywords: Calibration, Clay, CS655, Nebraska, Sensor, TDR315

\section{Introduction}

Accurate and continuous determination of soil water status is vital in many agricultural and hydrologic studies and can assist in making optimal irrigation management decisions. For example, monitoring of soil volumetric water content $\left(\theta_{\mathrm{v}}\right)$ can be used to trigger irrigation when soil water is depleted to a defined threshold based on crop and soil type. Electromagnetic (EM) sensors are widely used to monitor $\theta_{\mathrm{v}}$ due to ease of installation, rarity of regulatory and safety concerns, cost effectiveness, and convenience of frequent measurement. In addition, some EM sensors have the capability to measure additional soil properties such as temperature and apparent electrical conductivity $\left(\mathrm{EC}_{\mathrm{a}}\right)$-thus broadening the applicability of these sensors in both research and practice.

Electromagnetic soil water sensors estimate $\theta_{\mathrm{v}}$ by taking advantage of the high apparent relative permittivity $\left(\varepsilon_{\mathrm{ra}}\right)$ of water in comparison to that of other soil constituents. However, soil $\varepsilon_{\text {ra }}$ can be influenced by other factors such as temperature, salinity, textural composition, organic matter content (OMC), and bulk density $\left(\rho_{\mathrm{b}}\right)$ (Paige and Keefer, 2008). These factors might not be properly accounted for in the factory calibration of EM sensors. Some studies have proposed to correct for non-water influences on $\varepsilon_{\text {ra }}$ by developing soil specific calibrations. This approach requires capturing the response of EM sensors over a large $\theta_{\mathrm{v}}$ range in the field (Chávez and Evett, 2012; Kisekka et al., 2014; Michel et al., 2015; Rudnick et al., 2015; Singh et al., 2018) or in the laboratory (Adeyemi et al., 2016; Caldwell et al., 2018; Kargas 
and Soulis, 2019). Although soil specific calibrations have enabled the confident use of EM sensors at research sites, this approach might be infeasible for supporting wide adoption of EM sensors.

Other studies have proposed to correct for non-water influences on $\varepsilon_{\text {ra }}$ by developing one general calibration with built-in adjustments for such influences. This approach can be followed using empirical functions or physically-based dielectric mixing models (Dirksen and Dasberg, 1993; Or and Wraith, 1999; Schwartz et al., 2009). Jacobsen and Schjønning (1993) found that adding linear terms of $\rho_{b}$, $\mathrm{OMC}$, and clay content to the calibration equation produced a statistically significant improvement in the accuracy of $\theta_{\mathrm{v}}$ determined by time domain reflectometry (TDR) across 189 soil samples. Besides corrections for stable properties such as clay content, corrections for transient properties such as temperature (Western and Seyfried, 2005) and $\mathrm{EC}_{\mathrm{a}}$ (Kelleners et al., 2009) could also be included. If nonwater influences on $\varepsilon_{\mathrm{ra}}$ can be predicted well from easily measurable soil properties, then this approach may be feasible for supporting wide adoption of EM sensors. For example, Rüdiger et al. (2010) substantially improved $\theta_{\mathrm{v}}$ accuracy of CS616 sensors by using textural composition data to estimate the coefficients in empirical equations for temperature correction and soil moisture calibration instead of applying the factory calibration.

Specific objectives of this research were 1) to evaluate how differences in clay content, temperature, and salinity affect factory calibration accuracy of two relatively new reflectometers and 2) to develop for each of the two reflectometers a general non-soil specific calibration equation that adjusts its coefficients based on clay content alone. Readers should note that this study does not attempt to characterize fully these two specific reflectometers or to advance reflectometer physics in general. Instead, this study provides a preliminary idea of the factory calibration accuracy of two reflectometers under a variety of soil conditions and also a simple, user-friendly way to improve upon the factory calibration of two reflectometers across soils using an easily measurable property. Such outputs may not add significantly to the scientific understanding of reflectometers but may be extremely valuable to the practical use of reflectometers. 


\section{Materials and methods}

\subsection{Soils}

A laboratory study was conducted to analyze the performance of two recently developed EM sensors in five Nebraska soils. Soil was collected from particular depths at five sites across the state of Nebraska, USA, specifically to capture a wide range in clay content. Figure $\mathbf{1}$ shows the geographical distribution of these five sites and the corresponding soil associations. The collection sites were occurrences of the Valent (mixed, mesic Ustic Torripsamments), Cozad (coarse-silty, mixed, superactive, mesic Typic Haplustolls), Kuma (fine-silty, mixed, superactive, mesic Pachic Argiustolls), Hastings (fine, smectitic, mesic Udic Argiustolls), and Wymore (fine, smectitic, mesic Aquertic Argiudolls) soil series. The location, depth, and corresponding properties of each soil collection are presented in Table 1. Textural composition was measured using the hydrometer method by Ward Laboratories (Kearney, NE, USA) according to the Natural Resources Conservation Service (NRCS) classification system. The mean \pm standard deviation in clay content among the collected soils ranged from $5 \pm 1 \%$ for the Valent soil to $49 \pm 4 \%$ for the Wymore soil (Table 1 ). The corresponding textural classes were sand, sandy clay loam, clay loam, silty clay, and silty clay for the Valent, Cozad, Kuma, Hastings, and Wymore

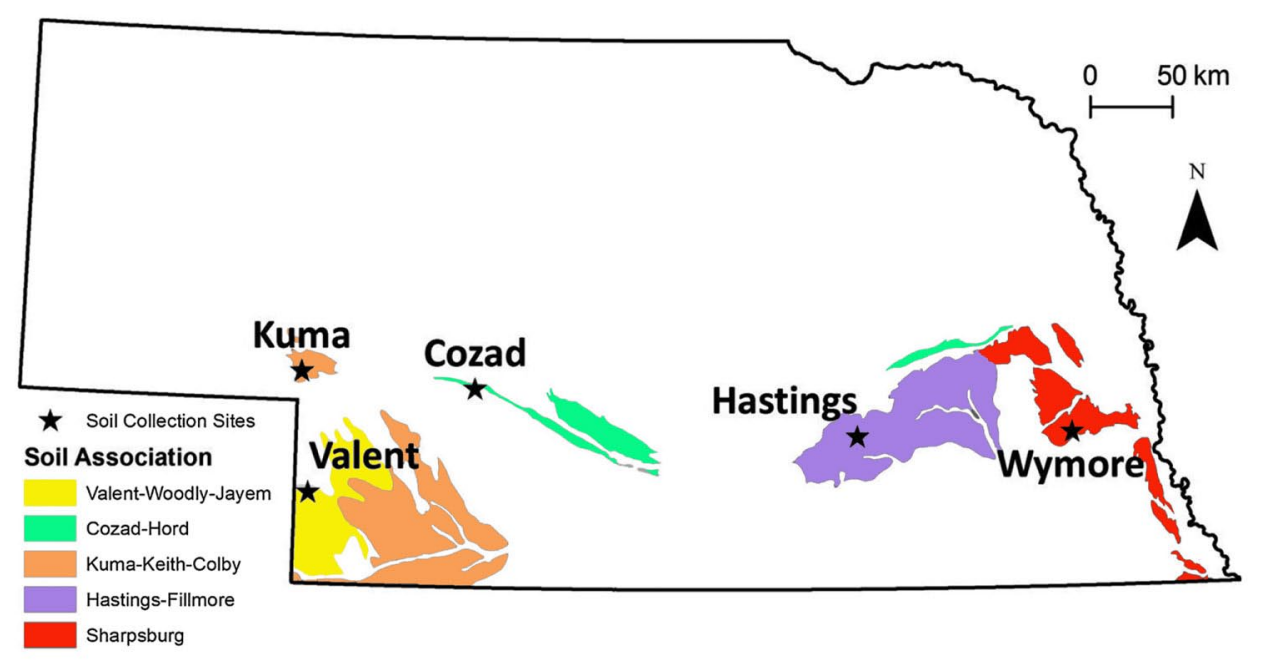

Figure 1. A map of Nebraska, USA, marking the five soil collection sites for this experiment and the five corresponding soil associations. 
soils, respectively, according to the NRCS classification system. Given the depths and soil series from which the soils were collected, typical cation exchange capacity at $\mathrm{pH} 7$ would be $0.016,0.170,0.212,0.279$, and $0.288 \mathrm{mmol} / \mathrm{g}$ for the Valent, Cozad, Kuma, Hastings, and Wymore soils, respectively, according to NRCS laboratory data (California Soil Resource Lab, 2019). Organic matter content was measured using the loss-on-ignition method by Ward Laboratories.

\subsection{Reflectometers}

Two recently developed reflectometers that are becoming more widely used were chosen for this study. One of the two sensor types investigated was TDR315/TDR315-L (Acclima, Meridian, ID, USA; Acclima, 2017) time domain reflectometers. Both TDR315 and TDR315-L are configured with three parallel rods (15 cm length by $3.2 \mathrm{~mm}$ diameter) serving as the waveguide. The sensor head for TDR315 has all necessary electronics and firmware to generate an EM pulse and to analyze the reflected waveform for determining the two-way travel time of the EM pulse, which is used to compute $\varepsilon_{\text {ra }}$. TDR315-L has similar electronics, firmware, and functionality as TDR315. However, TDR315-L consumes less power and is not capable of exporting waveforms. For both TDR315 and TDR315-L, $\theta_{\mathrm{v}}$ is calculated from $\varepsilon_{\mathrm{ra}}$ using a proprietary dielectric mixing model. Both TDR315 and TDR315$\mathrm{L}$ also use thermistors for determining temperature and use the Giese and Tiemann method for determining $\mathrm{EC}_{\mathrm{a}}$. For this study, TDR315 and TDR315-L were considered to be equivalent. Schwartz et al. (2016) observed that TDR315 can perform similarly to or better than conventional TDR. Specifically, TDR315 and conventional TDR reported "nearly indistinguishable" $\varepsilon_{\mathrm{ra}}$ values at the same known $\theta_{\mathrm{v}}$ value, but TDR315 was less sensitive than conventional TDR to the interference of salinity because TDR315 does not use long coaxial cables that can degrade high-frequency signals.

The other sensor type investigated in this study was CS655 (Campbell Scientific, Logan, UT, USA; Campbell Scientific, 2017) water content reflectometers (WCR). The CS655 is equipped with two parallel rods (12 cm length by $3.2 \mathrm{~mm}$ diameter) forming an open-ended transmission line. The CS655 determines 1) temperature by measuring thermistor resistance, 2) $\mathrm{EC}_{\mathrm{a}}$ by measuring the voltage ratio between 
a known excitation voltage and the measured attenuated voltage, and 3) period average by measuring the number of times per second that the reflection of the previous generated EM pulse returns to the sensor head to trigger the next generated EM pulse. The $\varepsilon_{\text {ra }}$ is calculated from period average using a factory calibrated empirical model that includes adjustments based on $\mathrm{EC}_{\mathrm{a}}$ (Campbell Scientific, personal communication, 2017; Caldwell et al., 2018), and then $\varepsilon_{\mathrm{ra}}$ is used to determine $\theta_{\mathrm{v}}$ using the Topp equation (Topp et al., 1980; Eq. (1)).

$$
\theta_{\mathrm{v}}=4.3 \times 10^{-6}\left(\varepsilon_{\mathrm{ra}}^{3}\right)-5.5 \times 10^{-4}\left(\varepsilon_{\mathrm{ra}}^{2}\right)+2.92 \times 10^{-2}\left(\varepsilon_{\mathrm{ra}}\right)-5.3 \times 10^{-2}
$$

\subsection{Experiment}

For each of the five collected soils with varying clay content, three vertical soil columns were constructed, each in a separate polyvinyl chloride (PVC) pipe section ( $0.223 \mathrm{~m}$ length by $0.255 \mathrm{~m}$ internal diameter). Landscape fabric and window screen were secured to the bottom end of each pipe section to serve as a water-permeable but soil-impermeable support. The collected soils were oven-dried at $105{ }^{\circ} \mathrm{C}$, ground, passed through a $2 \mathrm{~mm}$ sieve, and oven-dried at $105^{\circ} \mathrm{C}$ again. A metallic plate slightly smaller than the pipe internal diameter was attached to a hydraulic press and was used to pack the loose dry soil in five layers to the target $\rho_{\mathrm{b}}$ (Table 1) with a total height of $0.176 \mathrm{~m}$. Then, one TDR315-L (or TDR315 for three Cozad columns and one Kuma column) sensor and one CS655 sensor were inserted downward into each soil column until the bottom of the sensor head was flush with the top of the column. The dimensions of the soil columns and the placement of the two sensors were carefully designed so that the sensing volume of each sensor extended almost the full height of the column, remained entirely within the column, and did not include the hardware of the other sensor in the column. For simplicity, TDR315 and TDR315-L will be jointly referred to as TDR315 from here forward.

The soil columns were subjected to multiple saturation-drying cycles inside a temperature controlled room to study the $\theta_{\mathrm{v}}$ measurement accuracy of TDR315 and CS655 in soils with varying clay content. For every cycle, soil columns were wetted from the bottom up and then were allowed to drain briefly before the bottom was sealed with plastic film. In the saturation-drying cycle with constant temperature and 
Table 1 Location (latitude and longitude in World Geodetic System 1984) and depth of the five soil collections for this experiment, along with the textural composition, organic matter content $(\mathrm{OMC})$, and packed bulk density $\left(\rho_{\mathrm{b}}\right)$ of each soil; mean \pm standard deviation was determined from three random replicates for OMC and textural composition, but from the three columns for packed $\rho_{b}$.

\begin{tabular}{llllllll} 
Soil & Location & Depth $(\mathrm{m})$ & Sand (\%) & Silt (\%) & Clay (\%) & OMC (\%) & $\rho_{b}\left(\mathrm{~g} \mathrm{~cm}^{-3}\right)$ \\
\hline Valent & $40^{\circ} 30^{\prime} 5.7574^{\prime \prime} \mathrm{N}$ & $0.46-0.91$ & $88 \pm 1$ & $7 \pm 1$ & $5 \pm 1$ & $0.2 \pm 0.0$ & $1.85 \pm 0.01$ \\
& $101^{\circ} 57^{\prime} 15.5534^{\prime \prime} \mathrm{W}$ & & & & & & \\
Cozad & $41^{\circ} 5^{\prime} 10.6794^{\prime \prime} \mathrm{N}$ & $0.08-0.23$ & $55 \pm 3$ & $23 \pm 3$ & $22 \pm 0$ & $2.1 \pm 0.1$ & $1.37 \pm 0.01$ \\
& $100^{\circ} 46^{\prime} 16.6831^{\prime \prime} \mathrm{W}$ & & & & & & \\
Kuma & $41^{\circ} 9^{\prime} 39.7859^{\prime \prime} \mathrm{N}$ & $0.08-0.23$ & $35 \pm 2$ & $35 \pm 3$ & $30 \pm 2$ & $2.6 \pm 0.1$ & $1.38 \pm 0.01$ \\
& $102^{\circ} 11^{\prime} 26.5735^{\prime \prime} \mathrm{W}$ & & & & & & \\
Hastings & $40^{\circ} 50^{\prime} 6.6753^{\prime \prime} \mathrm{N}$ & $0.30-0.46$ & $14 \pm 3$ & $40 \pm 5$ & $46 \pm 2$ & $2.4 \pm 0.1$ & $1.31 \pm 0.01$ \\
& $98^{\circ} 0^{\prime} 52.1484^{\prime \prime} \mathrm{W}$ & & & & & & \\
Wymore & $40^{\circ} 50^{\prime} 37.7597^{\prime \prime} \mathrm{N}$ & $0.30-0.46$ & $8 \pm 4$ & $42 \pm 1$ & $49 \pm 4$ & $2.5 \pm 0.1$ & $1.34 \pm 0.00$ \\
& $96^{\circ} 28^{\prime} 12.8564^{\prime \prime} \mathrm{W}$ & & & & & & \\
\hline
\end{tabular}

no added salinity, room temperature was maintained at $35^{\circ} \mathrm{C}$, and saturation was performed using municipal tap water with electrical conductivity (EC) of 0.7 dS m m $^{-1}$ (Ward Laboratories, Kearney, NE, USA). In the saturation-drying cycle with two temperatures and no added salinity, room temperature alternated weekly between 35 and $24{ }^{\circ} \mathrm{C}$ (i.e., one week at $35{ }^{\circ} \mathrm{C}$, one week at $24{ }^{\circ} \mathrm{C}$, and repeat), and saturation was performed using municipal tap water. In the saturation-drying cycle with constant temperature and added salinity, room temperature was maintained at $35^{\circ} \mathrm{C}$, but saturation was performed using a solution prepared by adding $3.09 \mathrm{~g} \mathrm{~L}^{-1} \mathrm{CaCl}_{2}\left(\mathrm{EC}=5.0 \mathrm{dS} \mathrm{m}{ }^{-1}\right.$; Rumble, 2018) to municipal tap water.

Throughout each drying cycle, the output of the TDR315 and CS655 sensors were collected and recorded by a CR100o (Campbell Scientific, Logan, UT) datalogger every three minutes. Each soil column was weighed using a BSS-250 S-beam load cell connected to a TI-50oRFSS digital display (Transcell Technology, Buffalo Grove, IL). The frequency of weighing ranged from twice a day to once every two or three days, generally decreasing as the evaporation rate of the soil columns decreased. To obtain $\theta_{v}$ at the end of the entire experiment, the soil of each column was extracted and oven-dried at $105^{\circ} \mathrm{C}$, whereas each now-empty soil column setup (which included its two sensors) was weighed in the same way as when it contained the soil column. 


\subsection{Analysis}

To assess the $\theta_{\mathrm{v}}$ measurement accuracy of TDR315 and CS655 in the five soils with varying clay content, sensor $\theta_{v}$ output was compared against reference $\theta_{v}$ determined from soil column weight. Reference $\theta_{v}$ of each column at each weighing time was calculated using Eq. (2) and was matched with $\theta_{\mathrm{v}}$ reported by its two sensors at the closest timestamp:

$$
\text { reference } \theta_{v}=\frac{W_{\text {total }}-W_{\text {soil }}-W_{\text {setup }}}{\rho_{w} V_{\text {soil }}}
$$

where, $W_{\text {total }}$ is the total weight of the soil column, $W_{\text {soil }}$ is the weight of the dry soil in the column, $W_{\text {setup }}$ is the weight of the empty soil column setup, $\rho_{w}$ is the density of water $\left(\approx 1.0 \mathrm{~g} \mathrm{~cm}^{-3}\right)$, and $V_{\text {soil }}$ is the volume of the soil in the column.

Root mean square difference (RMSD; Eq. (3)) was calculated for each sensor in each soil over each drying cycle to indicate the absolute magnitude of differences between sensor $\theta_{v}$ and reference $\theta_{v}$ while penalizing larger differences.

$$
R M S D=\sqrt{\frac{\sum_{t}^{n} \sum_{i}^{m}\left[\left(s_{i, t}-r_{i, t}\right)^{2}\right]}{m n}}
$$

where, $i$ is the index of the soil column, $m$ is the number of soil columns per soil, $t$ is the index of the weighing time, $n$ is the number of weighing times during the drying cycle, $s_{i, t}$ is the sensor $\theta_{\mathrm{v}}$ of the $\mathrm{i}^{\text {th }}$ soil column at the $\mathrm{t}^{\text {th }}$ weighing time, and $r_{i, t}$ is the reference $\theta_{\mathrm{v}}$ of the $\mathrm{i}^{\text {th }}$ soil column at the $\mathrm{t}^{\text {th }}$ weighing time.

The effect of clay content and the potential interference of temperature and salinity on $\theta_{v}$ measurement accuracy of TDR315 and CS655 in the five soils were evaluated. To examine the effect of clay content under isothermal and non-saline conditions, the 33 weighing times from the drying cycle with constant temperature and no added salinity were analyzed. To examine the potential interference of temperature, the eight end-of-week weighing times from the drying cycle with two alternating weekly temperatures and no added salinity were analyzed. To examine the potential interference of 
salinity, the 33 weighing times from the drying cycle with constant temperature and no added salinity as well as the 40 weighing times from the drying cycle with constant temperature and added salinity were analyzed. In each of these analyses, the square root mixing model (Eq. (4)) was fitted to the reference $\theta_{\mathrm{v}}$ versus sensor $\varepsilon_{\mathrm{ra}}$ data from the soil columns. Then, analysis of variance (ANOVA) with a significance level $\alpha=0.05$ was conducted using statistical computing language $\mathrm{R}$ version 3.5.1 ( $\mathrm{R}$ Foundation for Statistical Computing, Wein, Austria). This procedure explored whether- within the ranges of clay content, temperature, and salinity evaluated in this experiment $-\theta_{\mathrm{v}}$ calibrations are statistically distinguishable when fitted separately to different levels of a non-water variable as when fitted jointly to all levels.

$$
\theta_{v}=a \sqrt{\varepsilon_{r a}}+b
$$

A general correction for clay content effects was proposed for $\theta_{\mathrm{v}}$ measurements by TDR315, and a general correction for clay content effects was proposed for $\theta_{\mathrm{v}}$ measurements by CS655. The basis of each correction was the 15 column specific square root mixing model calibration equations (Eq. (4)) relating sensor $\varepsilon_{\mathrm{ra}}$ to reference $\theta_{\mathrm{v}}$ during the drying cycle with constant temperature and no added salinity. Then, a set of polynomial regression interpolation equations was developed to estimate the value of each calibration coefficient (i.e., a and $b$ ) as a function of clay content. The polynomial order of each interpolation equation was chosen using leave-one-out cross-validation. The magnitude of improvement from applying the corrections would be best assessed by external validation in soils that were not part of this experiment. A comprehensive validation effort was prevented by the limited number of published studies that presented graphs or equations relating sensor $\varepsilon_{\mathrm{ra}}$ of TDR315 (Schwartz et al., 2016; Singh et al., 2018) or CS655 (Chávez and Evett, 2012; Caldwell et al., 2018; Singh et al., 2018; Kargas and Soulis, 2019) to reference $\theta_{v}$. Nonetheless, validation with these available studies generated preliminary information about the effectiveness of the general corrections for clay content effects. 


\section{Results and discussion}

\subsection{Effects of soil type on sensor performance}

The effects of soil type on sensor performance were analyzed using the drying cycle with constant temperature and no added salinity. Overall, the relationship between $\operatorname{TDR} 315 \theta_{\mathrm{v}}$ and reference $\theta_{\mathrm{v}}$ was relatively linear with slope near unity (Figure 2); however, differences among soils were present. In general, TDR315 slightly overestimated in the Valent soil by $0.013 \mathrm{~m}^{3} \mathrm{~m}^{-3}$ and underestimated in the Kuma soil by $0.018 \mathrm{~m}^{3} \mathrm{~m}^{-3}$. In the Cozad soil, TDR315 increasingly underestimated above but remained accurate below reference $\theta_{v}$ of $0.25 \mathrm{~m}^{3} \mathrm{~m}^{-3}$. The TDR315 response was similar in the Hastings and Wymore soils, which were closest in clay content. TDR315 $\theta_{v}$ was accurate above but underestimated below reference $\theta_{v}$ of $0.33 \mathrm{~m}^{3} \mathrm{~m}^{-3}$, with the magnitude of underestimation being larger for the Hastings than the Wymore soil. The general pattern for TDR315 was that as clay content increased, underestimation increased, especially at lower $\theta_{\mathrm{v}}$.
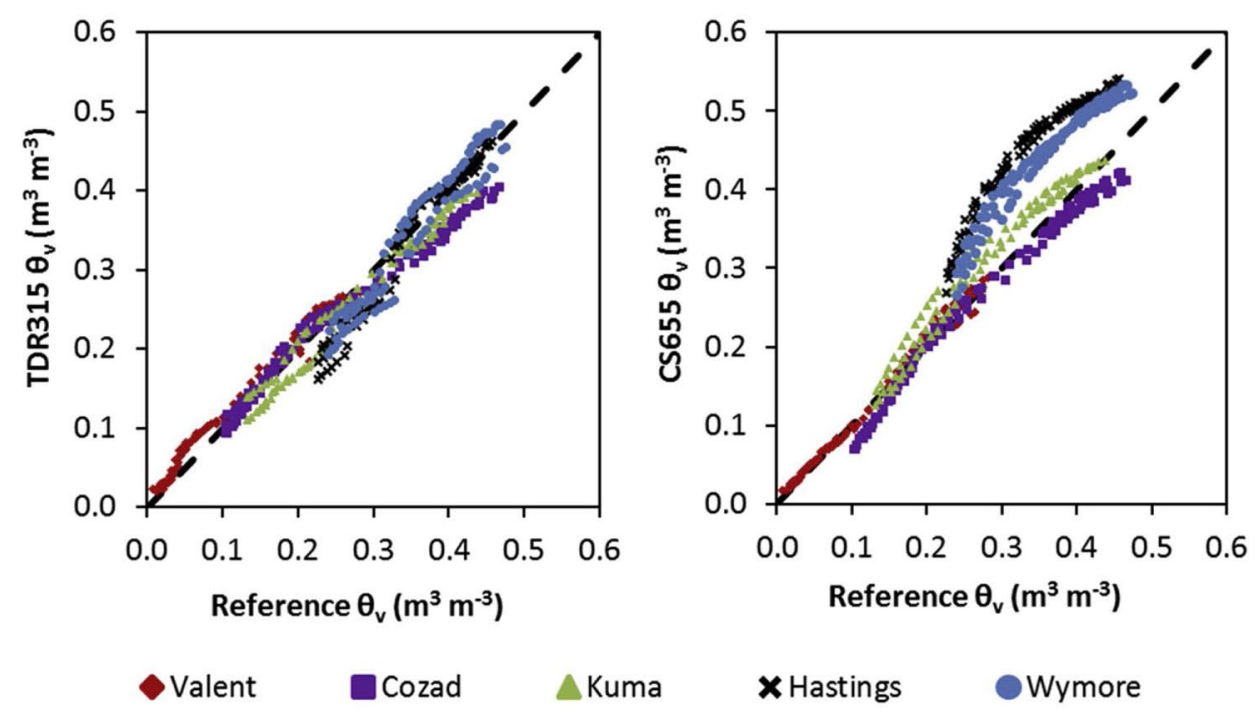

Figure 2. Scatterplots with 1:1 line comparing volumetric water content $(\theta \mathrm{v})$ reported by CSS655 and TDR315 against reference $\theta \mathrm{v}$ determined from soil column weight for the five soils during the drying cycle with constant temperature $\left(35^{\circ} \mathrm{C}\right)$ and no added salinity; each point represents one soil column at one measurement time. 
Underestimation of low $\theta_{\mathrm{v}}$ in clayey soils by TDR is well documented in the literature. A portion of water is bound to clay surfaces, and this bound water has much lower $\varepsilon_{\mathrm{ra}}$ than bulk water (Dirksen and Dasberg, 1993). Thus, a mixing model that does not consider bound water, including the TDR315 factory calibration and the Topp equation (Eq. (1)), would underestimate particularly at low $\theta_{\mathrm{v}}$. The sharp transition to underestimation below a threshold as observed for the Hastings and Wymore soils does not appear to be an artifact of the factory calibration. Using data from this study, the factory calibration was similar to the Topp equation when $\varepsilon_{\mathrm{ra}}<25$ (theoretically corresponding to $0.40 \mathrm{~m}^{3} \mathrm{~m}^{-3}$ ); only above this value, the factory calibration estimated a higher $\theta_{v}$ than the Topp equation. Sharp increases in underestimation by the Topp equation over a small $\theta_{v}$ range have been observed by others in clayey soils (Ponizovsky et al., 1999). Based on limited information, the sharp transition to underestimation would be attributed to the effect of increasing clay content.

In contrast, the relationship between CS655 $\theta_{\mathrm{v}}$ and reference $\theta_{\mathrm{v}}$ was clearly curvilinear for four out of five soils (Figure 2). Similar to TDR315, CS655 slightly overestimated in the Valent soil by approximately $0.005 \mathrm{~m}^{3} \mathrm{~m}^{-3}$. CS655 generally underestimated in the Cozad soil, and the underestimation increased as reference $\theta_{v}$ moved outside of $0.19-0.27 \mathrm{~m}^{3} \mathrm{~m}^{-3}$. Also, CS655 overestimated in the Kuma, Hastings, and Wymore soils; however, the overestimation peaked at intermediate reference $\theta_{v}$ for all three soils-0.26-0.27 $\mathrm{m}^{3} \mathrm{~m}^{-3}$ for Kuma, 0.32$0.34 \mathrm{~m}^{3} \mathrm{~m}^{-3}$ for Hastings, and $0.29-0.36 \mathrm{~m}^{3} \mathrm{~m}^{-3}$ for Wymore. Among these three soils, both the overall magnitude of overestimation and the most overestimated $\theta_{\mathrm{v}}$ were smallest for Kuma and largest for Hastings. Similar to TDR315, CS655 response was most similar between the Hastings and Wymore soils, which were closest in clay content. The pattern for CS655 was that as clay content increased, the overall magnitude of overestimation and the most overestimated $\theta_{\mathrm{v}}$ increased.

The influence of clay content on WCRs is also well-known in the literature. Kelleners et al. (2005) found that WCRs overestimated $\theta_{v}$ in sandy loam, loam, and silt loam soils due to dielectric dispersion and ionic conductivity. The effects of dielectric dispersion and ionic conductivity tend to increase with increasing clay content, so the increasing prominence of these two phenomena are likely explanations for increasing overestimation by CS655 with increasing clay content. In 
field research, overestimation by CS655 has been reported by Chávez and Evett (2012) in a clay loam soil, Kisekka et al. (2014) in a silt loam soil, Michel et al. (2015) in a silt loam over sand soil, and Singh et al. (2018) in a loam soil. These observations, which are mostly in finer textured soils, are consistent with the results of the present laboratory study.

Root mean squared difference (RMSD) values are consistent with the earlier discussion on the relationships between sensor and reference $\theta_{\mathrm{v}}$. For both CS655 and TDR315, sensors were observed to be most accurate $\left(<0.02 \mathrm{~m}^{3} \mathrm{~m}^{-3}\right)$ in the Valent soil, whose clay content was the least (Table 2). Most other sensor-soil combinations resulted in moderate RMSD between 0.02-0.04 $\mathrm{m}^{3} \mathrm{~m}^{-3}$. The large RMSD of CS655 in Hastings and Wymore ( $\left.>0.07 \mathrm{~m}^{3} \mathrm{~m}^{-3}\right)$ reflect the large overestimation that occurred throughout the drying cycle.

The diversity in response of both sensors among soils suggests that soil specific calibrations would be more appropriate than a soil blind calibration. Indeed, the ANOVA results indicated that soil specific square root mixing model calibrations provided a statistically significant improvement over soil blind square root mixing model calibrations for both sensors. For TDR315, this finding is in

Table 2 Root mean square difference comparing volumetric water content $(\theta \mathrm{v})$ reported by TDR315 and CS655 sensors against reference $\theta v$ determined from soil column weight in three drying cycles.

Root Mean Square Difference $\left(\mathrm{m}^{3} \mathrm{~m}^{-3}\right)$

\begin{tabular}{|c|c|c|c|c|c|}
\hline & Valent & Cozad & Kuma & Hastings & Wymore \\
\hline \multicolumn{6}{|c|}{ Drying cycle with constant temperature $\left(35^{\circ} \mathrm{C}\right)$ and no added salinity } \\
\hline TDR315 & 0.017 & 0.032 & 0.022 & 0.030 & 0.028 \\
\hline CS655 & 0.009 & 0.023 & 0.031 & 0.106 & 0.079 \\
\hline \multicolumn{6}{|c|}{$\begin{array}{l}\text { Drying cycle with two temperatures }\left(24 \text { and } 35^{\circ} \mathrm{C}\right) \text { and no added salinity } \\
24{ }^{\circ} \mathrm{C}\end{array}$} \\
\hline TDR315 & 0.010 & 0.011 & 0.024 & 0.027 & 0.027 \\
\hline CS655 & 0.003 & 0.028 & 0.028 & 0.113 & 0.083 \\
\hline \multicolumn{6}{|l|}{$35^{\circ} \mathrm{C}$} \\
\hline TDR315 & 0.008 & 0.011 & 0.023 & 0.025 & 0.021 \\
\hline CS655 & 0.004 & 0.022 & 0.036 & 0.132 & 0.101 \\
\hline \multicolumn{6}{|c|}{ Drying cycle with constant temperature $\left(35^{\circ} \mathrm{C}\right)$ and added salinity $\left(3.09 \mathrm{~g} \mathrm{~L}^{-1} \mathrm{CaCl}_{2}\right)$} \\
\hline TDR315 & 0.020 & 0.034 & 0.017 & 0.033 & 0.031 \\
\hline CS655 & 0.021 & 0.036 & 0.023 & 0.082 & 0.051 \\
\hline
\end{tabular}


Table 3 Estimated values of the linear $(a)$ and intercept $(b)$ coefficients in the soil specific square root mixing model calibration equation for CS655 and TDR315 sensors in the five soils: $\left(\right.$ Reference $\left.\theta_{\mathrm{v}}\right)=a \times \operatorname{sqrt}\left(\right.$ Sensor $\left.\varepsilon_{\mathrm{ra}}\right)+b$.

\begin{tabular}{lrrrrr} 
Soil & Sensor & $a\left(\mathrm{~m}^{3} \mathrm{~m}^{-3}\right)$ & $b\left(\mathrm{~m}^{3} \mathrm{~m}^{-3}\right)$ & $R M S D\left(\mathrm{~m}^{3} \mathrm{~m}^{-3}\right)$ & $R^{2}$ \\
\hline Valent & TDR315 & 0.115 & -0.187 & 0.013 & 0.978 \\
\multirow{4}{*}{ Cozad } & CS655 & 0.112 & -0.170 & 0.007 & 0.993 \\
\multirow{4}{*}{ Kuma } & TDR315 & 0.141 & -0.233 & 0.013 & 0.988 \\
& CS655 & 0.120 & -0.176 & 0.013 & 0.988 \\
\multirow{2}{*}{ Hastings } & TDR315 & 0.120 & -0.168 & 0.008 & 0.993 \\
\multirow{2}{*}{ Wymore } & CS655 & 0.110 & -0.179 & 0.015 & 0.975 \\
& TDR315 & 0.087 & -0.035 & 0.013 & 0.962 \\
& CS655 & 0.085 & -0.131 & 0.014 & 0.957 \\
& TDR315 & 0.092 & -0.058 & 0.018 & 0.932 \\
& CS655 & 0.087 & -0.118 & 0.011 & 0.974 \\
\hline
\end{tabular}

agreement with Ponizovsky et al. (1999), which reported clay content dependence of TDR calibration coefficients. For CS655, this finding is in agreement with Seyfried and Murdock (2001) and Chandler et al. (2004), both of which reported the need for soil specific calibration of WCRs. Using soil specific square root mixing model calibrations instead of soil-blind square root mixing model calibrations, overall RMSD across all soils would be lowered from 0.025 to $0.013 \mathrm{~m}^{3} \mathrm{~m}^{-3}$ for TDR315 and from 0.038 to $0.012 \mathrm{~m}^{3} \mathrm{~m}^{-3}$ for CS655. The soil specific calibrations generally reduced RMSD in each soil to less than $0.015 \mathrm{~m}^{3} \mathrm{~m}^{-3}$ (Table 3), and their coefficient values are listed in Table 3.

\subsection{Effect of temperature on sensor performance across soil types}

The effects of temperature on sensor performance across soil types were analyzed using the drying cycle with two temperatures $\left(24\right.$ and $35^{\circ} \mathrm{C}$ ) and no added salinity. Temperature appeared to exert a small yet soildependent effect on performance of TDR315 and CS655. For both sensors across soils, coefficients $a$ and $b$ of the square root mixing model (Eq. (4)) tend to be less positive and less negative, respectively, at $24^{\circ} \mathrm{C}$ than at $35^{\circ} \mathrm{C}$. For both sensors in the Valent soil, the same reference $\theta_{\mathrm{v}}$ tended to correspond to a slightly higher sensor $\theta_{\mathrm{v}}$ at $24{ }^{\circ} \mathrm{C}$ than at 35 ${ }^{\circ} \mathrm{C}$ (Figure 3). The temperature effect in the Cozad soil was inconsistent 

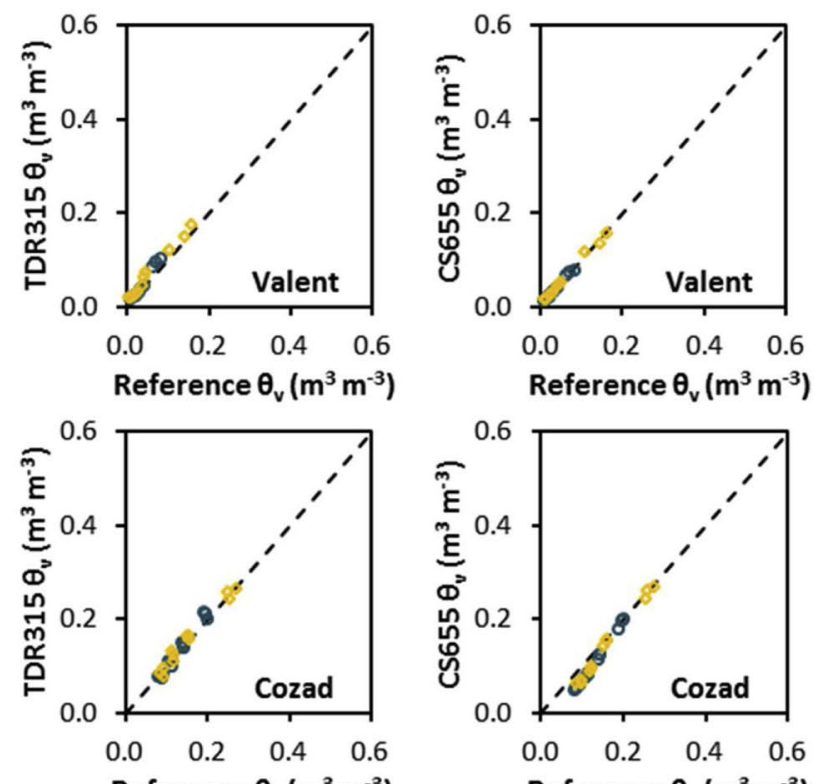

Reference $\theta_{v}\left(\mathrm{~m}^{3} \mathrm{~m}^{-3}\right)$

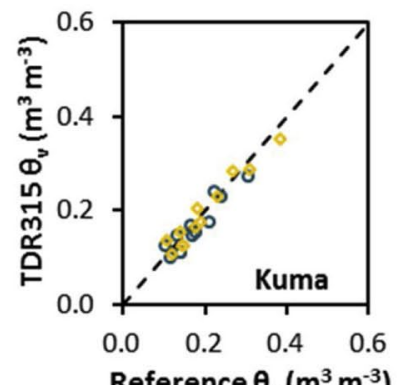

Reference $\theta_{\mathrm{v}}\left(\mathrm{m}^{3} \mathrm{~m}^{-3}\right)$
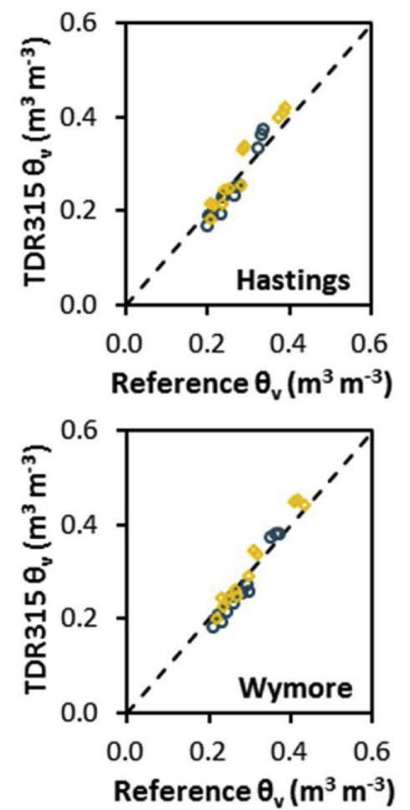

$024^{\circ} \mathrm{C}$
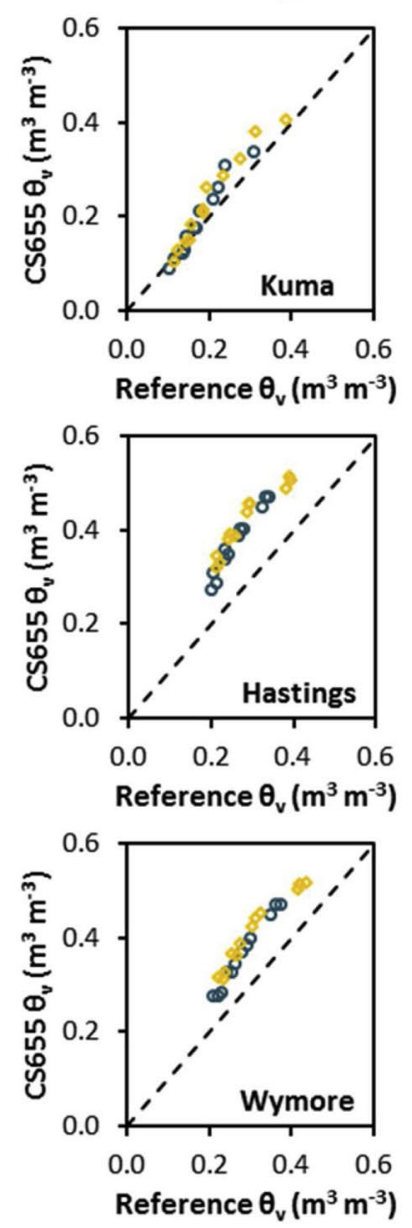

$35^{\circ} \mathrm{C}$
Figure 3. Scatterplots with 1:1 line comparing volumetric water content $\left(\theta_{\mathrm{v}}\right)$ reported by TDR315 and CS655 against reference $\theta_{\mathrm{v}}$ determined from soil column weight for the five soils during the drying cycle with two temperatures and no added salinity; each point represents one soil column at one measurement time after one week at the same temperature (24 or $35^{\circ} \mathrm{C}$ ). 
between the two sensors. For both sensors in Kuma, Hastings, and Wymore soils, the same reference $\theta_{\mathrm{v}}$ tended to correspond to a noticeably lower sensor $\theta_{\mathrm{v}}$ at $24{ }^{\circ} \mathrm{C}$ than at $35{ }^{\circ} \mathrm{C}$. Among these three soils, the magnitude of the temperature effect seemed to increase with increasing clay content for TDR315 but seemed to decrease with increasing clay content for CS655. The temperature effect caused RMSD for CS655 to be smaller at $24{ }^{\circ} \mathrm{C}$ than at $35{ }^{\circ} \mathrm{C}$ in these three soils because overestimation was reduced (Table 2). In all five soils, the temperature effect was more dramatic for CS655 than for TDR315.

Soil type dependence of temperature effects on sensor $\theta_{v}$ is primarily attributed to temperature dependence of both bound water content and bulk water permittivity (Wraith and Or, 1999). In clayey soils (e.g., Kuma, Hastings, Wymore), which provide large surface area for binding water, sensor $\theta_{v}$ generally increases with increasing temperature because the increase in $\varepsilon_{\mathrm{ra}}$ with the release of bound water outweighs the decrease in $\varepsilon_{\mathrm{ra}}$ with the lowering of bulk water permittivity. In soils with low clay content (e.g., Valent), which provide little surface area for binding water, sensor $\theta_{v}$ generally decreases with increasing temperature because the decrease in $\varepsilon_{\mathrm{ra}}$ with the lowering of bulk water permittivity outweighs the increase in $\varepsilon_{\text {ra }}$ with the release of bound water. These two trends explain well the observations from Figure 3. Though Wraith and Or (1999) developed their theory from TDR research, Seyfried and Murdock (2001) noticed the same two trends in WCR research. This is not surprising because both TDR and WCR respond to $\varepsilon_{\mathrm{ra}}$. Interestingly, the present finding of the larger temperature effect for CS655 than for TDR315 is in agreement with Blonquist et al. (2005), who found a larger temperature effect for a CS655 predecessor than for conventional TDR. Blonquist et al. (2005) also found that the magnitude of temperature effects were similar between sensors operating at higher EM frequencies than those operating at lower EM frequencies. Thus, the slightly larger temperature effect for CS655 than for TDR315 is perhaps a consequence of sensor design and firmware rather than EM frequency.

Literature also indicates that temperature effects on sensor $\theta_{\mathrm{v}}$ can depend on $\theta_{\mathrm{v}}$. This phenomenon has been reported by Pepin et al. (1995), Gong et al. (2003), and Adeyemi et al. (2016) for TDR and by Seyfried and Murdock (2001) and Western and Seyfried (2005) for WCR. Wraith and Or (1999) explained that because the ratio of bound 
water to bulk water decreases with increasing $\theta_{\mathrm{v}}$, the relative significance of bound water release versus declining bulk water permittivity can change with $\theta_{v}$. With four measurement times per temperature, the $\theta_{\mathrm{v}}$ dependence of temperature effects could not be properly evaluated in this study but may be present for TDR315 and/or CS655.

Results from ANOVA indicate that for CS655 but not TDR315, soil and temperature specific square root mixing model calibrations offered statistically significant improvement over soil specific but temperature blind square root mixing model calibrations. Using soil and temperature specific square root mixing model calibrations instead of soil specific but temperature-blind square root mixing model calibrations, overall RMSD across all soils would be lowered from 0.011 to $0.010 \mathrm{~m}^{3} \mathrm{~m}^{-3}$ for CS655 and almost unchanged at $0.011 \mathrm{~m}^{3} \mathrm{~m}^{-3}$ for TDR315. Unless the sensors are very near the surface, $11^{\circ} \mathrm{C}$ might be a likely range in topsoil temperature over an irrigation season rather than over the course of a day. The actual $\theta_{\mathrm{v}}$ uncertainty encountered within the timeframe of irrigation decision making (i.e., typically daily to weekly) as a result of soil temperature fluctuations would be even smaller than what the differences in overall RMSD suggest. Thus, temperature fluctuations between 24 and $35^{\circ} \mathrm{C}$ were inferred to cause potentially detectable but generally negligible effects on $\theta_{v}$ calibration of TDR315 and CS655 for irrigation management. Furthermore, because only two temperatures were evaluated in this study, the development of a temperature correction for the two sensors was not attempted.

\subsection{Effect of salinity on sensor performance across soil types}

The effects of salinity on sensor performance across soil types were analyzed by contrasting the drying cycle with constant temperature and added salinity against the drying cycle with constant temperature and no added salinity. For both TDR315 and CS655 across soils, the coefficients $a$ and $b$ of the square root mixing model (Eq. (4)) tended to be less positive and less negative, respectively, with added salinity than without-though the reverse was true for CS655 in the Valent soil. Salinity appeared to exert an opposite effect on performance of TDR315 than on performance of CS655. For TDR315, adding salinity slightly increased sensor $\theta_{v}$ in the Valent (mean difference $\left.(\mathrm{MD})=0.005 \mathrm{~m}^{3} \mathrm{~m}^{-3}\right)$, Kuma $\left(\mathrm{MD}=0.007 \mathrm{~m}^{3} \mathrm{~m}^{-3}\right)$, and Wymore $\left(\mathrm{MD}=0.011 \mathrm{~m}^{3} \mathrm{~m}^{-3}\right)$ soils (Figure 4$)$. This increase was concentrated at 


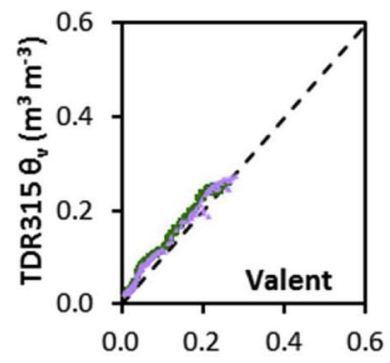

Reference $\theta_{v}\left(\mathrm{~m}^{3} \mathrm{~m}^{-3}\right)$
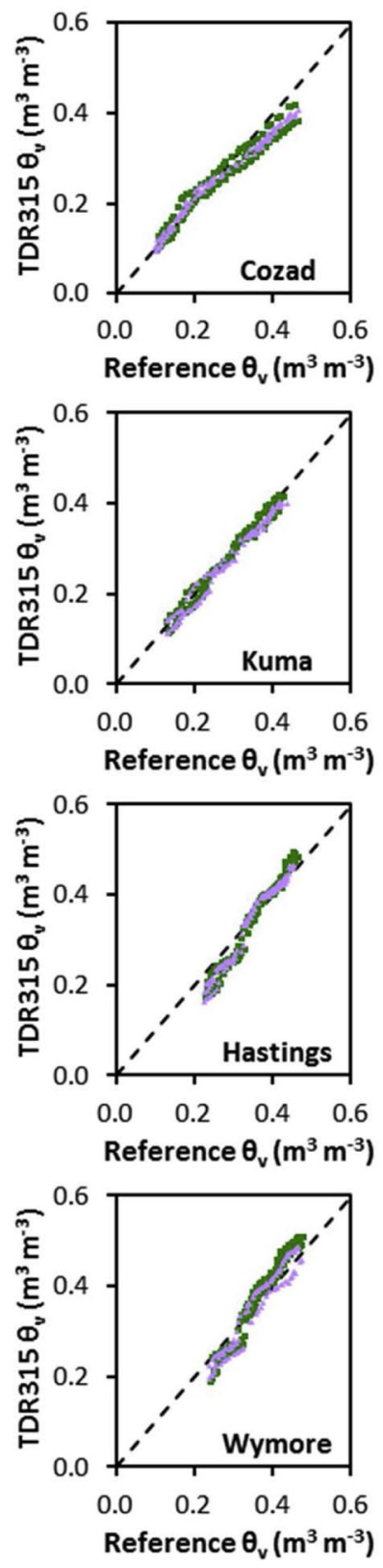

$\triangle$ No added salinity
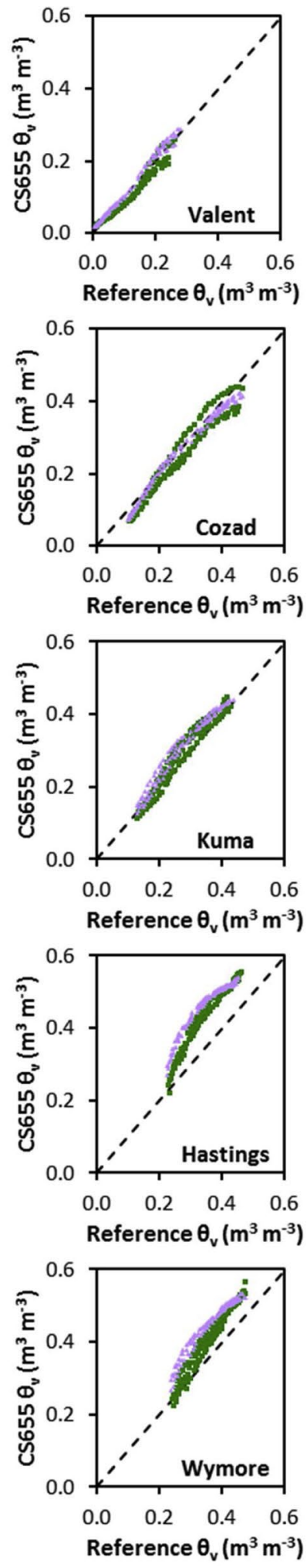

added salinity
Figure 4.

Scatterplots with 1:1 line comparing volumetric water content $\left(\theta_{v}\right)$ reported by TDR315 and CS655 against reference $\theta_{\mathrm{v}}$ determined from soil column weight for the five soils during the drying cycle with constant temperature ( $35^{\circ} \mathrm{C}$ ) and no added salinity versus during the drying cycle with constant temperature and added salinity; each point represents one soil column at one measurement time. 
intermediate $\theta_{\mathrm{v}}$ in the Valent soil but at high $\theta_{\mathrm{v}}$ in the Kuma and Wymore soils. For CS655, on the other hand, adding salinity decreased sensor $\theta_{\mathrm{v}}$ moderately in the Valent, Kuma, Hastings, and Wymore soils $\left(\mathrm{MD}=-0.020\right.$ to $\left.-0.034 \mathrm{~m}^{3} \mathrm{~m}^{-3}\right)$. The magnitude of decrease increased with increasing $\theta_{\mathrm{v}}$ in the Valent soil but decreased with increasing $\theta_{\mathrm{v}}$ in the Kuma, Hastings, and Wymore soils. For both sensors, large interreplicate differences overshadowed any salinity effects in the Cozad soil, while the largest salinity effect was observed in the Wymore soil.

Theory generally suggests that salinity should either do nothing or increase sensor $\theta_{v}$. One mechanism by which salinity can increase sensor $\theta_{\mathrm{v}}$ is by increasing imaginary permittivity. Imaginary permittivity increases with increasing apparent soil electrical conductivity and decreases with increasing EM frequency (Kelleners et al., 2005). At the same salinity level, sensors at lower frequencies will encounter a larger imaginary permittivity, which in turn will increase apparent permittivity to a greater extent. Again, because both TDR315 and CS655 are responding to apparent permittivity when determining $\theta_{v}$, this mechanism applies to both sensors. A mechanism by which salinity can increase WCR $\theta_{\mathrm{v}}$ specifically is by delaying its measurement of period average (Kelleners et al., 2005). As $\mathrm{EC}_{\mathrm{a}}$ increases, the reflection of the previous generated EM pulse will be further attenuated. WCRs rely on this reflection to reach a predefined voltage threshold before triggering the next generated EM pulse. Given the same travel speed, weaker reflections will take a longer time to reach that voltage threshold than stronger reflections and therefore will result in longer WCR period averages.

The observation that TDR315 experiences a smaller salinity effect than does CS655 is not surprising. TDR uses a range of relatively high frequencies, which reduces its sensitivity to salinity as observed by Blonquist et al. (2005). Earlier studies had claimed that TDR was insensitive to salinity (Topp et al., 1980; Nadler et al., 1991), but later studies have found otherwise (Wyseure et al., 1997; Topp et al., 2000; Schwartz et al., 2013). In the present study, average $\mathrm{EC}_{\mathrm{a}}$ reported by TDR315 for each soil at the first measurement time was 0.16-1.04 dS $\mathrm{m}^{-1}$ with no added salinity and 0.66-1.90 dS $\mathrm{m}^{-1}$ with added salinity. As explained by Rhoades et al. (1976), the same pore water EC corresponds to a higher $\mathrm{EC}_{\mathrm{a}}$ in clayey soils because these soils generally have higher $\theta_{v}$ and more conductive soil 
solid surfaces. In this study, $\mathrm{EC}_{\mathrm{a}}$ indeed increased with increasing $\theta_{\mathrm{v}}$ and loosely increased with increasing clay content. Wet Wymore soil witnessed not only the highest $\mathrm{EC}_{\mathrm{a}}$ but also the largest salinityinduced increase in TDR315 $\theta_{\mathrm{v}}$.

The observation that $\operatorname{CS} 655 \theta_{\mathrm{v}}$ was reduced by added salinity across multiple soils is surprising though. Blonquist et al. (2005) found that both period average and sensor $\theta_{\mathrm{v}}$ for a WCR predecessor of CS655 increased with increasing salinity as predicted by theory. In all soils of the present study, CS655 period average increased with added salinity at high $\theta_{v}$ as predicted by theory but decreased with added salinity at low and intermediate $\theta_{\mathrm{v}}$ contrary to theory. Unlike its predecessors, CS655 uses both $\mathrm{EC}_{\mathrm{a}}$ and period average to calculate sensor $\theta_{\mathrm{v}}$ (Campbell Scientific, 2017; Caldwell et al., 2018). Under the conditions of the study, the factory calibration decreases $\theta_{\mathrm{v}}$ as $\mathrm{EC}_{\mathrm{a}}$ increases given constant period average (Campbell Scientific, personal communication, 2017). This adjustment counteracted against the salinity-induced increase in period average at high $\theta_{\mathrm{v}}$ but exacerbated the salinity-induced decrease in period average at low and intermediate $\theta_{\mathrm{v}}$. The unexpected response of CS655 period average to salinity at low and intermediate $\theta_{\mathrm{v}}$ is troubling and needs to be further investigated.

Results from ANOVA indicate that for both TDR315 and CS655, soil and salinity specific square root mixing model calibrations offered statistically significant improvement over soil specific but salinity blind square root mixing model calibrations. The large number of measurement times in the two drying cycles certainly provided large statistical power for distinguishing differences. Using soil and salinity specific square root mixing model calibrations instead of soil specific but salinity- blind square root mixing model calibrations, overall RMSD across all soils would be lowered from 0.015 to $0.014 \mathrm{~m}^{3} \mathrm{~m}^{-3}$ for TDR315 and from 0.018 to $0.015 \mathrm{~m}^{3} \mathrm{~m}^{-3}$ for CS655. Although this difference in RMSD might not seem substantial, the aforementioned $\theta_{v}$ dependence on salinity effects means that the direction and magnitude of sensor error may be changing noticeably during the timeframe of irrigation decision making. Accounting for salinity would be recommended especially when using CS655 as compared with TDR315. Because only two salinity levels were evaluated in this study, the development of a salinity correction for the two sensors was not attempted. 


\subsection{Correction for clay content effects}

Considering the theories discussed above, clay content was deemed to be the most appropriate predictive variable for interpolating the trends in the $\theta_{\mathrm{v}}$ calibration for TDR315 and CS655 among the 15 soil columns of this study during the drying cycle with constant temperature and no added salinity. For both sensors, both coefficients a and $b$ of the square root mixing model were quadratically related to clay content (Figure 5). The procedure for obtaining coefficients of the $\theta_{v}$ calibration equation from Figure 5 will be hereafter referred to
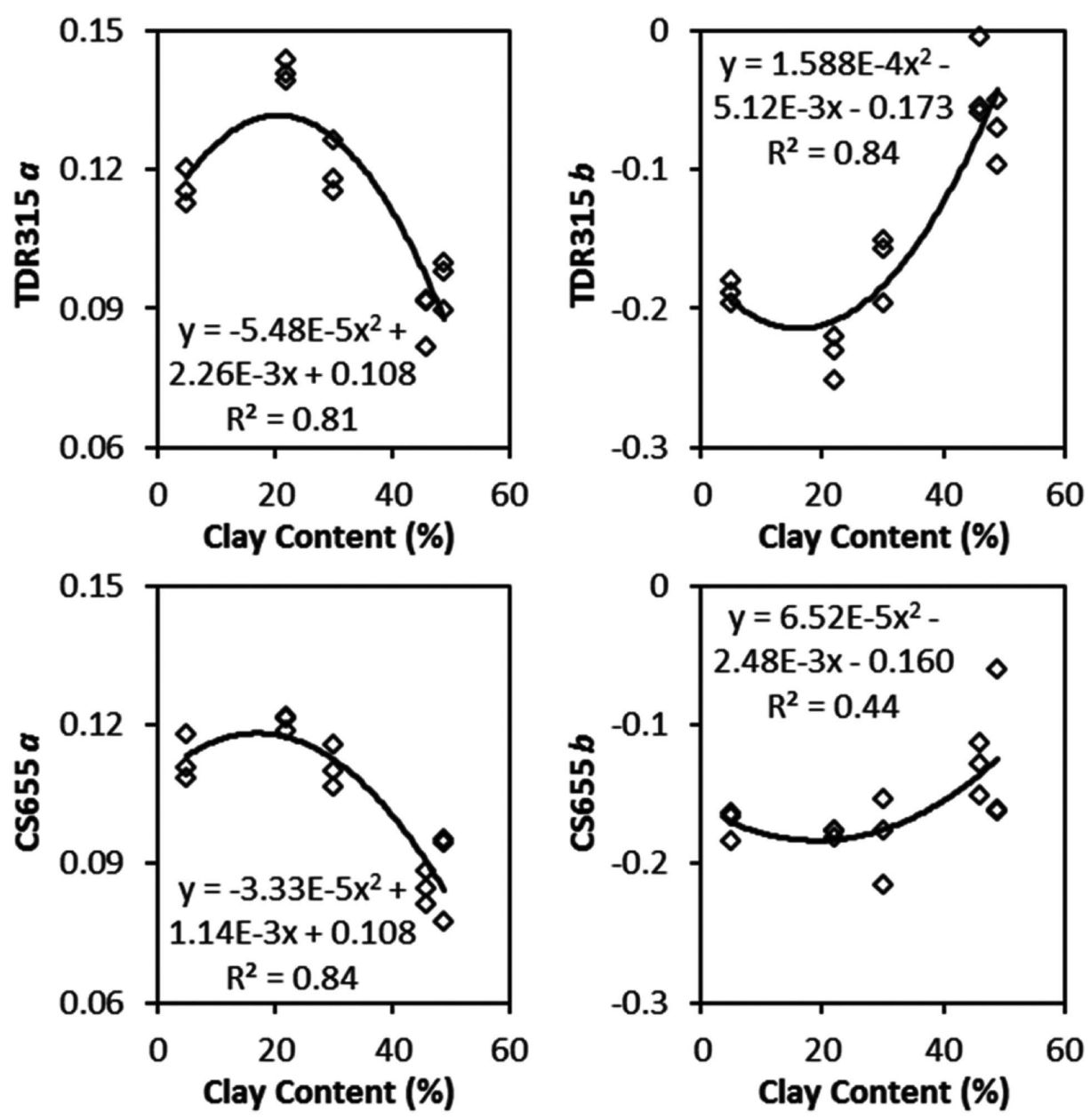

Figure 5. Relationships between clay content and the coefficients of the $\theta \mathrm{v}$ calibration equation ( (Reference $\left.\theta_{\mathrm{v}}\right)=a \times \operatorname{sqrt}\left(\right.$ Sensor $\left.\varepsilon_{\mathrm{ra}}\right)+b$ ) for TDR315 and CS655 in the 15 soil columns during the drying cycle with constant temperature and no added salinity. 
as the correction for clay content effects. If this correction was applied to the data from which it was developed, RMSD between sensor and reference $\theta_{\mathrm{v}}$ would decrease roughly by $36 \%$ for both TDR315 and CS655 as compared with using the factory calibration. The relative reduction in RMSD would be similar among soils for TDR315 but larger in clayeyer soils for CS655. Overall, these re-substitution results suggest that the correction for clay content effects is able to remove a substantial portion of the clay content effects on sensor $\theta_{\mathrm{v}}$ for both sensors.

External validation was conducted using the limited independent data from the literature (Chávez and Evett, 2012; Schwartz et al., 2016; Caldwell et al., 2018; Singh et al., 2018; Kargas and Soulis, 2019). Caldwell et al. (2018) experimented with different wetting/drying procedures to obtain a range of $\theta_{v}$. Here for external validation, only the data from the batch procedure was used after pooling soils $\mathrm{BaC}$ and $\mathrm{HnD}$ together and soils Fr and LuB together based on similar clay contents to assemble more data points for RMSD calculations. To avoid extrapolation, comparisons were restricted to the range in reference $\theta_{v}$ spanned by both the cycle with constant temperature and no added salinity (i.e., the dataset from which the correction for clay content effects was developed) and the external study of interest. In this cycle of the experiment, the ranges in average reference $\theta_{\mathrm{v}}$ were 0.011-0.272 $\mathrm{m}^{3} \mathrm{~m}^{-3}$ for the Valent soil, $0.106-0.457 \mathrm{~m}^{3} \mathrm{~m}^{-3}$ for the Cozad soil, $0.139-0.427 \mathrm{~m}^{3} \mathrm{~m}^{-3}$ for the Kuma soil, $0.229-0.455 \mathrm{~m}^{3} \mathrm{~m}^{-3}$ for

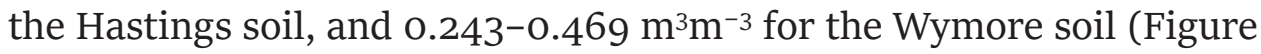
2). These ranges span and exceed those typically observed under irrigated conditions for each soil, respectively. Overall, the correction for clay content effects seemed to achieve increasing reduction in TDR315 and CS655 RMSD as clay content increased beyond 20\% (Figure 6). The five studies differed widely in both reference methods and wetting/drying methods. Chávez and Evett (2012) was a field study where CS655 was compared against conventional TDR with soil specific calibration, and the site was bare soil that included a repacked surface and was periodically flooded within a berm. Schwartz et al. (2016), Caldwell et al. (2018), and Kargas and Soulis (2019) were laboratory studies where TDR315 or CS655 was compared against known $\theta_{\mathrm{v}}$ in columns packed from uniform mixtures of water and dry soil. Singh et al. (2018) was a field study where TDR315 and CS655 were compared 


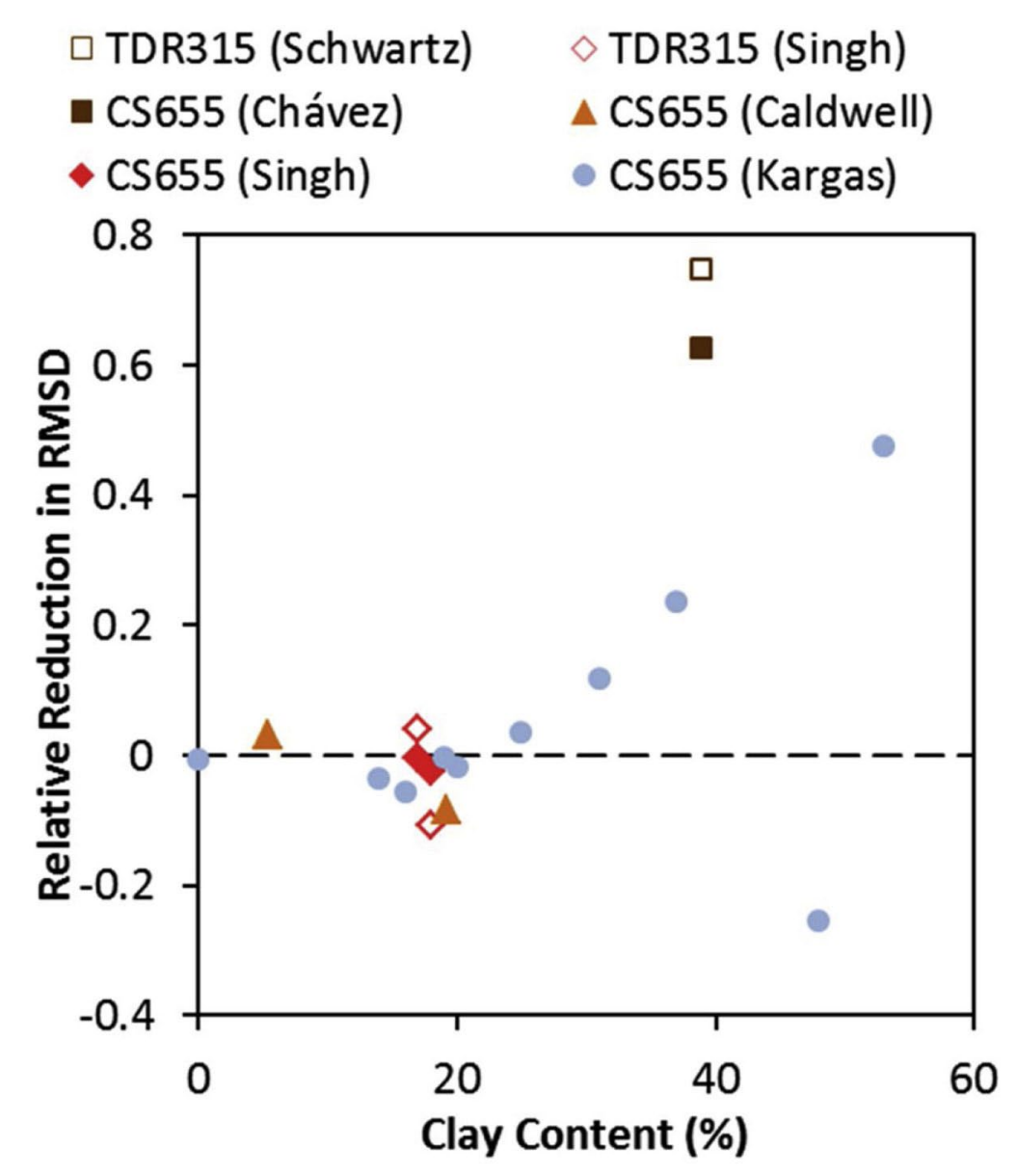

Figure 6. Relative reduction in root mean square difference (RMSD) achieved by applying the correction for clay content effects to independent studies from the literature-plotted against clay content of each soil of interest.

against a neutron moisture meter (NMM), and the site was no-till soybeans and was wetted by rainfall. The correction for clay content effects clearly improving $\theta_{\mathrm{v}}$ accuracy in multiple soils from contrasting experiments is definitely an optimistic finding.

Readers should be aware of issues related to the transferability of corrections for clay content effects. Because real permittivity and losses due to dielectric relaxation and ionic conductivity are both affected by specific surface area and not by the prevalence of clay sized particles, specific surface area is certainly a more direct predictor of "clay content effects" than is clay content itself. Yet because measurements of clay content are much more accessible than measurements of 
specific surface area, the correction developed in this study used clay content as the predictor. This choice would certainly limit the transferability of the correction to soils with distinctly different clay mineralogies. Nevertheless, except where information about local clay mineralogy is widely available to guide the estimation of specific surface area from clay content (Or and Wraith, 1999), most users of reflectometers may not be able to apply corrections that used specific surface area as the predictor. Finally, some EM sensors preferentially respond to small wetter and drier spots in natural soil and thus overestimate $\theta_{\mathrm{v}}$ (Logsdon, 2009), so caution should be exercised when considering the transfer of corrections between laboratory and field.

\section{Conclusions}

A laboratory study was conducted at the West Central Research and Extension Center, North Platte, NE, USA, to analyze the performance of two recently developed electromagnetic (EM) sensors - TDR315 and CS655 in five Nebraska soils. The study evaluated how differences in clay content (ranging from 5 to $49 \%$ ), temperature ( 24 versus $35^{\circ} \mathrm{C}$ ), and salinity (o versus $3.09 \mathrm{~g} \mathrm{~L}^{-1}$ of added $\mathrm{CaCl}_{2}$ ) affected volumetric water content $\left(\theta_{\mathrm{v}}\right)$ reported by the EM sensors using their factory calibrations. For all five soils, the relationship between TDR315 and reference $\theta_{v}$ was relatively linear with slope near unity. The general pattern for TDR315 was that as clay content increased, underestimation increased especially at lower $\theta_{\mathrm{v}}$. In contrast, the relationship between CS655 and reference $\theta_{\mathrm{v}}$ was curvilinear for four out of the five soils; as clay content increased, the overall magnitude of overestimation and the most overestimated $\theta_{\mathrm{v}}$ increased for CS655. In all five soils, the temperature effect was more dramatic for CS655 than for TDR315. With respect to the Kuma, Hastings, and Wymore soils, the magnitude of the temperature effect increased with increasing clay content for TDR315 but decreased for CS655. Although the effect of temperature on $\theta_{\mathrm{v}}$ was statistically detectable for one of the two sensors, the effect is expected to be negligible for most irrigation management applications. Salinity had an opposite effect on the performance of TDR315 than CS655. For TDR315, adding salinity slightly increased sensor $\theta_{v}$ in the Valent, Kuma, and Wymore soils. This increase was 
concentrated at intermediate $\theta_{\mathrm{v}}$ in the Valent soil but at high $\theta_{\mathrm{v}}$ in the Kuma and Wymore soils. For CS655, adding salinity decreased sensor $\theta_{v}$ moderately in the Valent, Kuma, Hastings, and Wymore soils. The magnitude of decrease increased with increasing $\theta_{v}$ in the Valent soil but decreased in the Kuma, Hastings, and Wymore soils. Accounting for the effects of salinity is recommended especially when using CS655 as compared with TDR315.

In this study, clay content was deemed to be an appropriate predictive variable for interpolating the trends in the $\theta_{\mathrm{v}}$ calibration for TDR315 and CS655; therefore, a correction for clay content effects was established. Applying the correction to the data from which it was developed, RMSD between sensor and reference $\theta_{\mathrm{v}}$ decreased roughly 36\% for both TDR315 and CS655. External validation of the correction was also conducted using limited independent data from the literature. The correction improved the results in soils with more than $20 \%$ clay content but not in less clayey soils. These encouraging findings highlight the promise of simple, empirical corrections such as the one developed in this study. Colleagues are invited to validate and refine this correction further. Future efforts should focus on developing corrections for clay content effects in the field and especially on bridging the advancements of modern soil physics with the practical challenges and constraints of most reflectometer users.

Acknowledgments This study is based upon work that was jointly supported by the National Institute of Food and Agriculture, U.S. Department of Agriculture (USDANIFA), under award number 2016-68007-25066, "Sustaining agriculture through adaptive management to preserve the Ogallala aquifer under a changing climate"; USDA-NIFA Hatch Project number 1015698, "Integrating Hydrological Modeling and Characterization Approaches across Scales to Understand the Effects of Efficient Irrigation Management on Groundwater/Surface Water Systems"; United States Geological Survey Section 104B under award number G16APooo68; and the Daugherty Water for Food Global Institute. The authors are grateful to Nebraska producers Phil Christenson and Tim Varilek as well as university farm managers Stuart Hoff and Toby Spiehs for authorizing soil collection. The authors thank Turner Dorr, Jacob Nickel, and Alan Boldt for assisting the authors on this project. The authors especially appreciate both the editor who gave the original manuscript a chance to be revised and the reviewer whose technical expertise and constructive criticism propelled remarkable improvements to the manuscript. 


\section{References}

Acclima, 2017. User Manual: True TDR-315, TDR-315L \& TDR-310S. http://www. acclima.com/prodlit/TDR\%20User\%20Manual.pdf

Adeyemi, O., Norton, T., Grove, I., Peets, S., 2016. Performance evaluation of three newly developed soil moisture sensors. CIGR-AgEng Conference Paper. June.

Blonquist, J.M., Jones, S.B., Robinson, D.A., 2005. Standardizing characterization of electromagnetic water content sensors: part 2. Evaluation of seven sensing systems. Vadose Zone J. 4, 1059-1069.

Caldwell, T.G., Bongiovanni, T., Cosh, M.H., Halley, C., Young, M.H., 2018. Field and laboratory evaluation of the CS655 soil water content sensor. Vadose Zone J. 17, 170214. https://doi.org/10.2136/vzj2017.12.0214

California Soil Resource Lab. (2019). SoilWeb. http://casoilresource.lawr.ucdavis. edu/gmap/

Campbell Scientific, 2017. CS650 and CS655 Water Content Reflectometers. https://s.campbellsci.com/documents/us/manuals/cs650.pdf

Chandler, D.G., Seyfried, M., Murdock, M., McNamara, J.P., 2004. Field calibration of water content reflectometers. Soil Sci. Soc. Am. J. 68, 1501-1507.

Chávez, J.L., Evett, S.R., 2012. Using soil water sensors to improve irrigation management. Proceedings of the 24th Annual Central Plains Irrigation Conference. pp. 187-202.

Dirksen, C., Dasberg, S., 1993. Improved calibration of time domain reflectometry soil water content measurements. Soil Sci. Soc. Am. J. 57, 660-667.

Gong, Y., Cao, Q., Sun, Z., 2003. The effects of soil bulk density, clay content and temperature on soil water measurement using time-domain reflectometry. Hydrol. Process. 17, 3601-3614.

Jacobsen, O.H., Schjønning, P., 1993. A laboratory calibration of time domain reflectometry for soil water measurement including effects of bulk density and texture. J. Hydrol. (Amst) 151, 147-157.

Kargas, G., Soulis, K.X., 2019. Performance evaluation of a recently developed soil water content, dielectric permittivity, and bulk electrical conductivity electromagnetic sensor. Agric. Water Manag. 213, 568-579. https://doi. org/10.1016/j.agwat.2018.11.002

Kelleners, T.J., Seyfried, M.S., Blonquist Jr., J.M., Bilskie, J., Chandler, D.G., 2005. Improved interpretation of water content reflectometer measurements in soils. Soil Sci. Soc. Am. J. 69, 1684-169o.

Kelleners, T.J., Paige, G.B., Gray, S.T., 2009. Measurement of the dielectric properties of Wyoming soils using electromagnetic sensors. Soil Sci. Soc. Am. J. 73, 1626-1637.

Kisekka, I., Aguilar, J., Lamm, F., Rogers, D., 2014. Using soil water and canopy temperature to improve irrigation scheduling for corn. In: Proceeding for the 2014 Irrigation Association Conference. Phoenix, Arizona.

Logsdon, S.D., 2009. CS616 calibration: field versus laboratory. Soil Sci. Soc. Am. J. $73,1-6$. 
Michel, A.J., Brown, H.E., Gillespie, R.N., George, M.J., Meenken, E.D., 2015. Automated measurement of crop water balances under a mobile rain-exclusion facility. Agron. N. Z. 45, 39-46.

Nadler, A., Dasberg, S., Lapid, I., 1991. Time domain reflectometry measurements of soil water content and electrical conductivity of layered soil columns. Soil Sci. Soc. Am. J. 55, 938-943.

Or, D., Wraith, J.M., 1999. Temperature effects on soil bulk dielectric permittivity measured by time domain reflectometry: a physical model. Water Resour. Res. 53 (2), 371-383. https://doi.org/10.1029/1998WRgoooo8

Paige, G.B., Keefer, T.O., 2008. Comparison of field performance of multiple soil moisture sensors in a semi-arid rangeland. J. Am. Water Resour. Assoc. 44 (1), 121-135.

Pepin, S., Livingston, N.J., Hook, W.R., 1995. Temperature-dependent measurement errors in time domain reflectometry determinations of soil water. Soil Sci. Soc. Am. J. 59, 38-43.

Ponizovsky, A.A., Chudinova, S.M., Pachepsky, Y.A., 1999. Performance of TDR calibration models as affected by soil texture. J. Hydrol. (Amst) 218, 35-43.

Rhoades, J.D., Raats, P.A.C., Prather, R.J., 1976. Effects of liquid-phase electrical conductivity, water content, and surface conductivity. Soil Sci. Soc. Am. J. 40, 651-655.

Rüdiger, C., Western, A.W., Walker, J.P., Smith, A.B., Kalma, J.D., Willgoose, G.R., 2010. Towards a general equation for frequency domain reflectometers. J. Hydrol. (Amst) 383, 319-329.

Rudnick, D.R., Djaman, K., Irmak, S., 2015. Performance analysis of capacitance and electrical resistance-type soil moisture sensors in a silt loam soil. Trans. ASABE 58 (3), 649-665.

Rumble, J.R. (ed.), 2020. Electrical conductivity of aqueous solutions. In: CRC Handbook of Chemistry and Physics, 99th ed. CRC Press/Taylor \& Francis, Boca Raton, FL

Schwartz, R.C., Evett, S.R., Bell, J.M., 2009. Complex permittivity model for time domain reflectometry soil water content sensing: II. Calibration. Soil Sci. Soc. Am. J. 73 (3), 898-909. https://doi.org/10.2136/sssaj2008.0195

Schwartz, R.C., Cassanova, J.J., Pelletier, M.G., Evett, S.R., Baumhardt, R.L., 2013. Soil permittivity response to bulk electrical conductivity for selected soil water sensors. Vadose Zone J. 12 (2). https://doi.org/10.2136/vzj2012.0133

Schwartz, R.C., Evett, S.R., Anderson, S.K., Anderson, D.J., 2016. Evaluation of a direct-coupled time-domain reflectometry for determination of soil water content and bulk electrical conductivity. Vadose Zone J. 15 (1).

Seyfried, M.S., Murdock, M.D., 2001. Response of a new soil water sensor to variable soil, water content, and temperature. Soil Sci. Soc. Am. J. 65, 28-34.

Singh, J., Lo, T., Rudnick, D.R., Dorr, T.J., Burr, C.A., Werle, R., Shaver, T.M., Muñoz-Arriola, F., 2018. Performance assessment of factory and field calibrations for electromagnetic sensors in a loam soil. Agric. Water Manag. 196, 87-98. https://doi.org/10.1016/j.agwat.2017.10.020 
Topp, G.C., Davis, J.L., Annan, A.P., 1980. Electromagnetic determination of soil water content: measurements in coaxial transmission lines. Water Resour. Res. $16,574-582$.

Topp, G.C., Zegelin, S., White, I., 200o. Impacts of the real and imaginary components of relative permittivity on time domain reflectometry measurements in soils. Soil Sci. Soc. Am. J. 64 (4), 1244-1252. https://doi. org/10.2136/sssaj2000.6441244X

Western, A.W., Seyfried, M.S., 2005. A calibration and temperature correction procedure for the water-content reflectometer. Hydrol. Process. 19, 3785-3793.

Wraith, J.M., Or, D., 1999. Temperature effects of soil bulk dielectric permittivity measured by time domain reflectometry: experimental evidence and hypothesis development. Water Resour. Res. 35 (2), 361-369.

Wyseure, G.C.L., Mojid, M.A., Malik, M.A., 1997. Measurement of volumetric water content by TDR in saline soils. Eur. J. Soil Sci. 48, 347-354. 